\title{
Antiretroviral medication treatment for all HIV-infected individuals: a protocol using innovative multilevel methodologies to evaluate New York City's universal ART policy among problem substance users
}

Aimee N. C. Campbell ${ }^{*}$, Don Des Jarlais², Cooper Hannah ${ }^{3}$, Sarah Braunstein ${ }^{4}$, Susan Tross ${ }^{1,5}$, Laura Kersanske ${ }^{4}$, Christine Borges ${ }^{4}$, Martina Pavlicova ${ }^{6}$, Kevin Jefferson ${ }^{3}$, Howard Newville $^{5}$, Laurel Weaver ${ }^{5}$ and Margaret Wolff ${ }^{5}$

\begin{abstract}
Background: The intersection of HIV-related health outcomes and problem substance use has been well documented. New York City continues to be a focal point of the U.S. HIV epidemic. In 2011, the NYC Department of Health and Mental Hygiene (NYC DOHMH) issued a recommendation that all HIV infected individuals should be offered antiretroviral therapy (ART) regardless of CD4 cell count or other indicators of disease progression. This policy is based in the concept of "treatment as prevention," in which providing ART to people living with HIV (PLWH) greatly reduces the likelihood of HIV transmission, while also improving individual health. The "ART for ALL" (AFA) study was designed to inform modifications to and identify gaps in the implementation of universal ART, and specifically to help guide allocation of resources to obtain local policy goals for increasing viral suppression among PLWH who have problem substance use.
\end{abstract}

Methods/Design: The AFA Study is informed by two complementary frameworks: Glasgow and colleagues' RE-AIM model, a multi-level framework developed to guide the evaluation of implementation of new policies, and Bronfrenbrenner's ecological systems model, which conceptualizes the bi-directional interplay between people and their environment. Using multi-level data and mixed methods, the primary aims of the AFA Study are to assess rates of viral load suppression, using the NYC HIV Surveillance Registry, within 12 months of HIV diagnosis with (a) yearly cohorts of high-risk-to-transmit, difficult-to-treat, substance using patients recruited from NYC Sexually Transmitted Disease clinics and a large detoxification unit and (b) yearly cohorts of all newly HIV diagnosed people in NYC. Further goals include (c) recruiting cross-sectional samples of HIV/AIDS service providers to assess ART initiation with problem substance users and d) examining geographic factors that influence rates of viral load suppression. An Implementation Collaborative Board meets regularly to guide study procedures and interpret results.

Discussion: The AFA Study has the unique strength of accessing and analyzing data at multiple levels using mixed methodology, taking advantage of NYC DOHMH biomedical surveillance data. If successful, others may benefit from lessons learned to inform local and state policies to improve the health of PLWH and further reduce HIV transmission.

Keywords: HIV/AIDS, Adherence, Antiretroviral therapy, Substance use, Affordable care act

\footnotetext{
* Correspondence: anc2002@cumc.columbia.edu

${ }^{1}$ Department of Psychiatry, Columbia University Medical Center, New York

State Psychiatric Institute, 1051 Riverside Drive, Box 120, New York, NY 10032,

USA

Full list of author information is available at the end of the article
} 


\section{Background}

The intersection of HIV-related health outcomes, such as HIV transmission and substance abuse, has been well documented. Problem substance is indicated in both HIV prevention and treatment strategies. Beyond the risk of increased rates of HIV transmission due to injection-related behaviors (e.g., sharing needles), sex under the influence of drugs and alcohol is frequently associated with HIV transmission [1-6]. Persons with problem substance use are also less likely to engage in treatment for HIV infection [7-9], to be retained in treatment [10], and to adhere to antiretroviral treatment (ART) schedules [11, 12]. It is also well established that substance users are at higher risk for sexually transmitted infections (STI) [4, 13-15]. Prevalence of recent substance use in STI clinic samples include up to $50 \%$ reporting heavy alcohol use in the past 30 days and $47 \%$ with illicit substance use in the past year [16]. Sexually transmitted infections biologically facilitate HIV transmission [17-19], and diagnosis of a sexually transmitted infection is an indicator of risky sexual behavior. Thus, ART initiation programs should target and respond to the needs of substance users [20].

\section{Shifting context of the NYC HIV epidemic}

New York City continues to be a focal point of the U.S. HIV epidemic; however, significant shifts in the epidemic are underway. In 2010, there were 3353 new HIV infections in NYC [21]. As in the United States more broadly, HIV infection in NYC is heavily concentrated in racial/ ethnic minority communities [10, 22]. In 2010, African American/Black and Hispanic/Latino individuals made up 47 and $31 \%$, respectively, of new HIV diagnoses in NYC [21], while comprising 23 and $29 \%$, respectively, of the NYC population [23]. Since 2010, there have been continued decreases in the number of HIV diagnoses in NYC. In 2013, there were a total of 2832 cases of new HIV diagnoses in NYC, a reduction from 2990 in 2012 and 3225 in 2011 [21].

Viral load suppression within 12 months of diagnosis has also been increasing over time. Data from 2006 to 2009 and published in 2013 indicate that achieving viral suppression ( $\leq 200$ copies $/ \mathrm{mL}$ ) within 12 months of diagnosis was $39.8 \%$ (36 \% in 2006 and $45 \%$ in 2009) [24]. More recently, according to data from 2013, viral suppression within 12 months was $69 \%$ [25]. This proportion was moderated by age (younger people have lower rates of suppression) and CD4 count at diagnosis (those with greater than 500 cells/mm3 were less likely to be suppressed) [25]. Durable viral suppression (DVS), a marker of high engagement in care, has also shown similar increases over the last decade. Only $38.6 \%$ of people living with HIV (PLWH) reached DVS in 2006-2007, with DVS defined as all viral load tests being $\leq 200$ copies/mL over the 2 year period among people with 2 or more viral load tests [26]. In 2010-2011, the proportion with DVS had increased to $52 \%$ - an overall increase of $37 \%$ from 2006-07 to 2010-11 [27].

Longitudinal data from a recent analysis of persons who inject drugs, recruited from a large detoxification unit and methadone maintenance program in NYC, also demonstrated that the percentage of persons at risk for transmitting HIV (defined as those HIV positive and engaged in distributive needle sharing) decreased from $21 \%$ in 1990-1994 to $2 \%$ in 2007-2014 [28]. These promising trajectories suggest a shift in the HIV epidemic among persons who inject drugs.

Despite these improvements, much work remains, especially among Black and Latino young men who have sex with men (MSM) and individuals with problem substance use. To change the HIV landscape in a lasting way at least $80 \%$ of PLWH must be virally suppressed $[25,29]$. It is likely that additional innovative practices, guidelines, and policies will be needed to increase the proportion of PLWH who reach viral suppression within 12 months of diagnosis.

\section{Universal antiretroviral therapy: treatment as prevention} In December 2011, the New York City Department of Health and Mental Hygiene (NYC DOHMH) issued a recommendation that all HIV infected individuals should be offered ART regardless of CD4 cell count or other indicators of disease progression [30]. This policy is based in the concept of "treatment as prevention," in which providing ART to HIV seropositives greatly reduces the likelihood of HIV transmission [31-34], while at the same time improving individual health outcomes [35-37]. In combination with other HIV prevention programs in New York (e.g., Seek, Test, Treat, and Retain [20, 33, 38, 39], free condom distribution, syringe exchange [40, 41], opioid agonist treatment $[42,43]$, and most recently pre-exposure prophylaxis [PrEP] for high-risk individuals) - the universal ART policy aims to improve outcomes along the HIV care cascade [44] and help to facilitate realization of an AIDSfree generation.

NYC's implementation of universal HIV treatment has been gradual. Following the initial release of early treatment recommendation in December 2011, there were accompanying press coverage and FAQ's for providers and consumers, revisions to the early treatment brochure distributed to testing and Ryan White funded clients (underor uninsured clients who receive federal funding for HIV health care delivery), and the development of a texting campaign for young MSM to encourage early treatment. Universal ART was added to pre-existing efforts such as the 2010 New York State law that health providers of all types offer HIV testing to consumers aged 13-64 (and younger and older patients at high risk) at all visits [45]. Multi-level, borough-wide campaigns using mass media, provider training, community outreach, and other 
methods, urged HIV testing [46]. In 2013, the NYC DOHMH Bureau of Sexually Transmitted Disease (STD) Control assessed their HIV primary care referrals to ensure providers were implementing new recommendations and, specifically that referrals were made only to providers using universal ART guidelines. A primary initiative that has recently been implemented by the NYC DOHMH is to provide data on viral load and linkage to care to Health and Hospitals Corporation and other high-volume HIV care providers. Reporting of viral load outcomes will be a critical feedback loop to providers for increasing awareness of their patients' outcomes and working to achieve higher suppression rates.

Placing larger numbers of HIV diagnosed patients on ART and providing support services so that they achieve viral suppression will undoubtedly require additional resources. The new policy will be incorporated into new contracts between NYC DOHMH and AIDS service providers for use of Ryan White funds. These new contracts will require that services be billed to Medicaid when possible, so that Ryan White funds may be used for those not Medicaid eligible (and who do not have private health insurance).

\section{Affordable care act legislation}

Concurrent implementation of Patient Protection and Affordable Care Act [47] legislation will also be an important factor in the evaluation of universal ART among PLWH in NYC. The NYC DOHMH is in the process of planning how to respond to the potential for the Affordable Care Act to alter the landscape of HIV treatment and care, especially through Medicaid expansion and its integration with state-based insurance exchanges. For example, since Ryan White funding has a payment of last resort requirement, Ryan White funded services will need to adjust to the current implementation of Medicaid Health Homes, including income eligibility threshold changes for Medicaid recipients and the implementation of Health Insurance Exchanges.

\section{An opportunity to evaluate the "ART for ALL" policy: AFA study}

In the context of a shifting HIV epidemic in NYC and the overall changes across the healthcare continuum, the "ART for ALL" (AFA) Study was designed to not only provide critical information that could be used to help achieve policy goals for increasing viral suppression among PLWH, but to remain flexible within the changing context of the NYC HIV epidemic. The AFA Study has the unique strength of accessing and analyzing data at multiple levels, with mixed methods. It also has the advantage of integrating NYC DOHMH biomedical surveillance data, both with individual behavioral assessments and geospatial (i.e., neighborhood) variables, to provide information about potential moderators and mediators of HIV treatment outcomes. Data collected from the AFA Study will be used to inform modifications to or identify gaps in the implementation of universal ART, and in particular, to help guide allocation of resources to obtain local policy goals. The research will be conducted with the NYC DOHMH as a full partner and includes a Collaborative Board with service providers, clinical researchers, and consumers to review data and make formal recommendations. If successful, there is potential that others may benefit from lessons learned to improve the health of people with HIV and reduce further HIV transmission - leading the way towards an AIDS-free generation.

The primary aims of the AFA Study are to assess rates of viral load suppression within 12 months of diagnosis with (a) yearly cohorts of high risk to transmit, difficult to treat, substance using patients and (b) yearly cohorts of all newly HIV diagnosed people in NYC. Further goals include (c) recruiting cross-sectional samples of HIV/ AIDS service providers to assess, via quantitative and qualitative methods, ART initiation with problem substance users and organizational factors which facilitate or impede ART initiation; and d) examining geographic factors (i.e., United Hospital Fund (UHF) level data) that influence rates of viral load suppression. NYC DOHMH HIV surveillance data allow for the tracking of key clinical outcomes (e.g., via viral load and CD4 count data). The study is intended to inform implementation of the universal ART policy, as well as treatment changes brought about by the full implementation of the Affordable Care Act, and guide allocation of resources to reach this policy goal (see Fig. 1). As such, the AFA Study was purposefully designed to be flexible and adjust to the changing HIV landscape in NYC. The design, especially eliciting ongoing Implementation Collaborative Board feedback, also allows for modification of sampling and methods.

\section{Methods/Design \\ Conceptual framework}

The AFA Study is informed by two complementary frameworks: the RE-AIM [48] and ecological systems [49] models (see Fig. 2). The RE-AIM model [48] is a multi-level framework developed to guide the evaluation of implementation of new policies. RE-AIM is comprised of five essential dimensions: 1 ) Reach - measure of percentage (and characteristics) of people who are affected by the policy; 2) Efficacy - positive and negative individual behavioral, quality of life, satisfaction, and physiologic outcomes of the policy; 3) Adoption - proportion and representativeness of participating and non-participating providers/settings; 4) Implementation - extent to which the policy or intervention is delivered as intended, including participant adherence and provider fidelity; and 5) Maintenance - long-term participant outcomes 


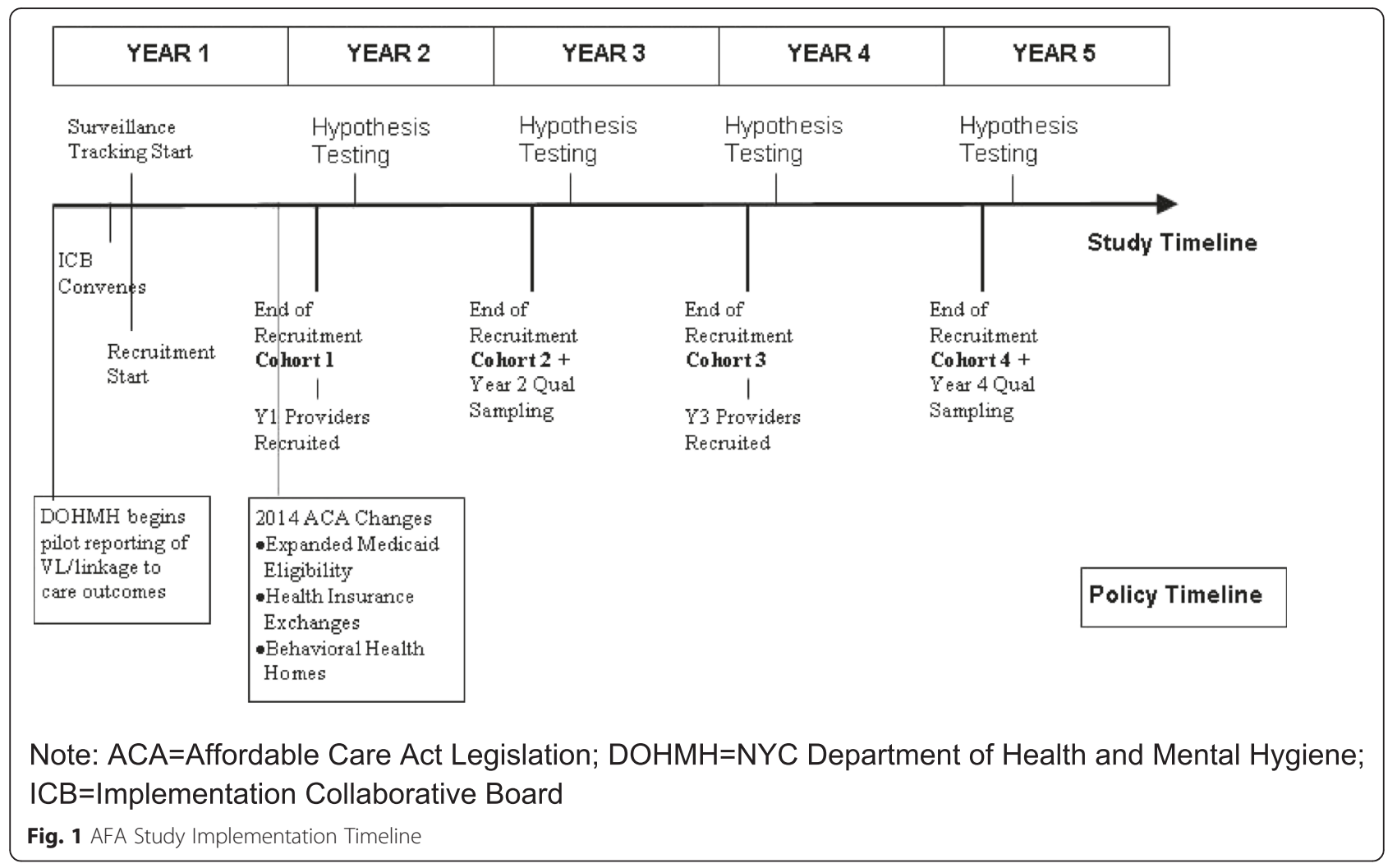

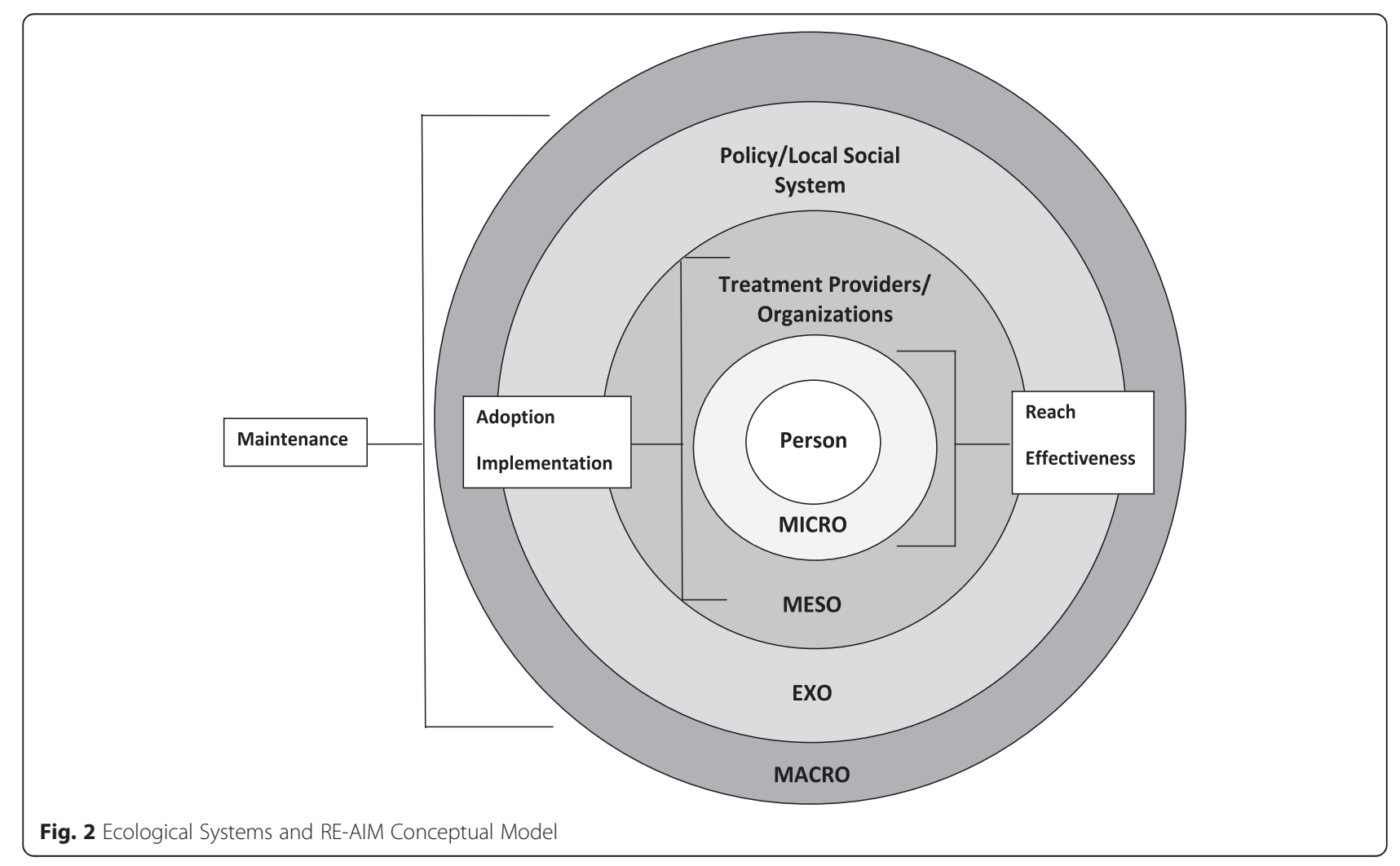


and the extent to which policies become part of routine practice.

In this study, the RE-AIM model is utilized within the context of the ecological systems model [49], which conceptualizes the bi-directional interplay between people and their environment. The ecological systems model is useful for explaining syndemic health disparities associated with HIV (e.g., substance abuse, mental health, sexually transmitted infections $[50,51]$ and specifically how multi-level factors influence individual HIV treatment linkage, retention, and ultimately viral load suppression. Micro-level systems include the individual and his/her immediate interpersonal interaction within family or social supports, school, work, and services. "Proximal processes", or regular reciprocal interactions within an individual's immediate environment that vary in duration, frequency, interruption, timing, and intensity [52-54], are an important part of the microsystem. The mesosystem is comprised of interactions between microsystem settings. Provider and organizational settings fall within the mesosystem (e.g., provider knowledge). The exosystem includes dimensions of the larger social system in which the individual is embedded, but over which he or she has limited control. Place characteristics (e.g., poverty rates, the epidemiologic environment, such as HIV prevalence, and the health service environment, such as spatial access to healthcare) are aspects of the exosystem. The macrosystem covers overarching "prototypical" culture and structures (e.g., economic systems, social norms), often implicit in social practice [55]. In the proposed study, micro, meso, exo and macro system environments will be evaluated among clients, providers, and the broader HIV treatment system, including Affordable Care Act legislation.

\section{Micro-system: STD/detox cohort and NYC surveillance cohorts}

Individual-level data will be obtained from two separate cohorts: (1) STD/Detox and (2) HIV surveillance (i.e., all new HIV diagnoses in NYC). The STD/Detox cohort allows for the collection of comprehensive data from a subgroup of HIV-infected individuals, while the HIV surveillance data allows for examination of the entire population of newly HIV-infected individuals during the study.

\section{STD/detox cohort}

The STD/Detox Cohort, as the name implies, will be recruited from (1) NYC DOHMH STD clinics, primarily from the two largest clinics located in Manhattan and Brooklyn, and (2) the 139-bed inpatient general drug detoxification unit at Mount Sinai Beth Israel Medical Center in Manhattan. Eligible participants 1) have a new HIV diagnosis or have been previously diagnosed but have been out of care in the last year (i.e., not seen by an
HIV primary care provider), 2) report problem substance use, and 3) are able to speak and understand English. HIV diagnoses will be confirmed through a match of study data with the NYC DOHMH HIV surveillance registry. Problem substance use is broadly defined to ensure range of severity: injection drug use or injection drug use combined with male to male HIV sexual transmission risk; illicit drug use in the prior 12 months, including club drugs; or heavy drinking (i.e., more than four drinks for men and more than three drinks for women on one occasion, following NIAAA guidelines [56]) in the past 30 days.

Recruitment locations were selected because these patients are likely to be at high-risk of transmitting HIV to others (i.e., high rates of problem substance use [16] and actively engaged in unsafe sexual behaviors) and they will provide representation of a spectrum of substance use problems - i.e. from more severe substance use disorders on the detox unit to variable severity at the STD clinics. Demographic profiles using prior research and STD electronic medical record data from 2012 suggest that $90 \%$ of participants will be male; $55 \%$ of STD clients will be 29 years of age or younger, while the mean age of detox clients will be 34 years and $35 \%$ will identify as Hispanic, $31 \%$ Black, and $27 \%$ White [57]. In prior research, younger HIV seropositive individuals have demonstrated greater delay in treatment linkage [58].

Four yearly cohorts of patients are being recruited (2014-2017; target $N=300,75$ per cohort). It is expected that approximately 200 patients will be recruited from STD clinics and 100 from detox. In 2011, 447 clients received a positive test for HIV in NYC STD Clinics; 244 were from the two largest clinics (55\%). Approximately 4500 clients are seen in the Beth Israel Detox Program each year; $10 \%$ are HIV positive [28].

At first contact with the client, research staff will provide a brief description of the study and ask if the client is willing to provide contact information. The research assistant will contact interested clients by telephone and will obtain the client's verbal consent for a short screening interview. The screen will determine eligibility and the following information will be collected: age, sex, gender, race/ethnicity, transmission risk category, previous HIV testing, and assessment of problem substance use. Following screening, eligible and interested clients provide written informed consent and are formally enrolled in the study. All enrolled participants complete a baseline assessment and four follow-up assessments at 6-month intervals over the next two years. All measures will be administered at all assessment time points (except for static demographic characteristics). All assessment visits will take about $90 \mathrm{~min}$. This study was approved by the Mount Sinai St. Luke's/Roosevelt Institutional Review Board (IRB), Mount Sinai Beth Israel IRB, and the NYC DOHMH IRB. Table 1 details domains, variables, and measurement tools 
Table 1 Measurement domains, variables, and data source by Ecological System and RE-AIM outcomes for patient, provider and geographic analyses

\begin{tabular}{|c|c|}
\hline Indicator/domain & Variable(s) \\
\hline \multicolumn{2}{|c|}{ Patient level: Person (MICRO): Reach, Efficacy, Maintenance } \\
\hline $\begin{array}{l}\text { Demographic } \\
\text { Characteristics }\end{array}$ & $\begin{array}{l}\text { Age, race/ethnicity, sex, gender, marital status, living situati } \\
\text { dependents, education and income, insurance, legal, } \\
\text { immigration status, religion and spirituality, medical history }\end{array}$ \\
\hline \multirow[t]{2}{*}{$\begin{array}{l}\text { Primary Outcome: Viral } \\
\text { load suppression }\end{array}$} & $\begin{array}{l}\text { Durable Suppression: two consecutive tests with } \leq 200 \\
\text { HIV-1 RNA copies per mL of plasma }\end{array}$ \\
\hline & $\begin{array}{l}\text { Viral Suppression: most recent test with } \leq 200 \text { HIV-1 RNA } \\
\text { copies per } \mathrm{mL} \text { of plasma }\end{array}$ \\
\hline $\begin{array}{l}\text { Secondary Outcome: } \\
\text { Linkage }\end{array}$ & Occurrence of first CD4NL test date after study enrollment \\
\hline $\begin{array}{l}\text { Secondary Outcome: } \\
\text { ART Initiation }\end{array}$ & ART regimen initiated \\
\hline $\begin{array}{l}\text { Secondary Outcome: } \\
\text { Treatment retention }\end{array}$ & $\begin{array}{l}\text { Sustained engagement or regular care, } \geq 1 \text { primary care } \\
\text { visit in each } 6 \text { month interval }\end{array}$ \\
\hline $\begin{array}{l}\text { Secondary Outcome: } \\
\text { HIV medication (ART) } \\
\text { Adherence }\end{array}$ & Adherent at threshold ( $\geq 90 \%)$ for all ART medications \\
\hline $\begin{array}{l}\text { Secondary Outcome: } \\
\text { Quality of Life }\end{array}$ & Health-related quality of life \\
\hline $\begin{array}{l}\text { Secondary Outcome: } \\
\text { Sexual and Drug Use Risk }\end{array}$ & Sexual partners, unprotected sex acts, needle/works sharing \\
\hline Predictor: Substance Use & $\begin{array}{l}\text { Illicit drug use (days), alcohol (days, \# drinks), substance } \\
\text { use disorder severity }\end{array}$ \\
\hline Predictor: Mental Health & Psychological distress \\
\hline Predictor: Social Support & Social network size/quality; disclosure of HIV to family/friends \\
\hline $\begin{array}{l}\text { Predictor: Service } \\
\text { Utilization }\end{array}$ & $\begin{array}{l}\text { Medical, substance abuse treatment, mental health, } \\
\text { case management, Ryan White-funded services }\end{array}$ \\
\hline Predictor: Attitudes & Attitudes towards primary HIV provider professional \\
\hline Predictor: ART Barriers & Barriers to ART adherence \\
\hline Predictor: Stigma & Experiences and perceived discrimination and stigma \\
\hline Predictor: Knowledge & HIV treatment knowledge \\
\hline
\end{tabular}

PROVIDER/PRIMARY CARE LEVEL (MESO): Adoption, Implementation, Maintenance

Professional

Characteristics

Predictor: Organizational characteristics

Predictor: Knowledge

Predictor: Attitudes
Age, sex, race/ethnicity, education, years since terminal degree, HIV care (years in current position/providing HIV care, caseload)

Location, service type, size, staffing, service flexibility, impac of ACA, staff attributes, organizational culture and climate

Knowledge of ART guidelines; perceived self-efficacy to follow ART guidelines

Attitudes and ideology toward patients and the provider/ patient relationship, including patients with substance use problems
Measurement source

AFA Survey

HIV Surveillance Registry

HIV Surveillance Registry

AFA Survey

HIV Surveillance Registry

Visual Analogue Scale [72-74]

EQ-5D EuroQoL [75]

Modified Risk Assessment Battery and Risk Behavior Scale $[76,77]$

TLFB [78]; QuickTox 8-panel Drug Screen Dipcard; Fagerstrom Test for Nicotine Dependence [79]; DSM-V Checklist for Substance Use Disorders [80]

Kessler10 [81], Personality Inventory for DSM-V Brief Form [82]; Posttraumatic Stress Symptom Screener [80]

MOS Social Support Survey [83]; HIV Disclosure Status Questionnaire [84]

Modified Treatment Services Review [85]

Attitudes Towards HIV Health Care Providers Scale [86] Medical Mistrust Index [87]

Adherence Barriers Questionnaire [88]

MIDUS Daily Discrimination Scale [89]; Social Impact Scale [90]

HIV Treatment Related Knowledge Inventory [91, 92]

AFA Survey

Perceived Environmental Uncertainty (unpublished measure, D'Aunno, 2013); Change Survey [93, 94]; Survey of Organizational Attributes for Primary Care [95]; Medical Group Practice Culture [96]

AFA Survey

Attitudes About Patients with Substance Use Disorders [97, 98]; Patient-Practitioner Orientation Scale [99] 
Table 1 Measurement domains, variables, and data source by Ecological System and RE-AIM outcomes for patient, provider and geographic analyses (Continued)

\begin{tabular}{|c|c|c|}
\hline \multicolumn{3}{|c|}{ NEIGHBORHOOD/GEOGRAPHIC LEVEL (EXO): Reach, Efficacy, Maintenance } \\
\hline $\begin{array}{l}\text { Predictor: Socioeconomic } \\
\text { Conditions }\end{array}$ & $\begin{array}{l}\text { Poverty rate; median income; unemployment rate; } \\
\text { educational attainment; percent of residents who are } \\
\text { non-Hispanic White }\end{array}$ & 2011 American Community Survey, 5-year estimate [100] \\
\hline Predictor: Health Service & Spatial access to HIV primary care & $\begin{array}{l}2013 \text { Data pull from HIVMA, AAHIVM, NYSDOH AIDS Institute } \\
\text { Provider Database }\end{array}$ \\
\hline Predictor: Social Disorder & Off-premises alcohol outlet density; vacant housing & $\begin{array}{l}\text { 2009-2012 U.S. Census Bureau's Zip Code Business Patterns } \\
\text { [101-103]; 2009-2010, } 2012 \text { USPS Delivery Stats Product } \\
\text { [104-106] }\end{array}$ \\
\hline Predictor: Social Cohesion & $\begin{array}{l}\% \text { of housing units leased; \% households that moved } \\
\text { into the neighborhood in last year }\end{array}$ & 2011 American Community Survey, 5-year estimate [107] \\
\hline
\end{tabular}

across data sources based on the RE-AIM dimensions. For patient-level data collection, the dimensions Reach and Efficacy will be assessed. Maintenance will be assessed using patient follow-up data.

\section{NYC HIV surveillance cohort}

The HIV Surveillance data will serve as the source of data for the STD/Detox patient-level outcomes, as well as be used to create yearly NYC surveillance cohorts (i.e., all new HIV positive individuals in NYC). The HIV Epidemiology \& Field Services Program at the NYC DOHMH is authorized by the NYS Department of Health to conduct HIV/AIDS surveillance in NYC. Diagnostic providers are required by law to report all new diagnoses of HIV and AIDS and all laboratories are required to report positive HIV antibody tests (e.g., Western Blot, Immunofluorescence Assay, Multispot) as well as all viral loads, CD4 counts, and genetic resistance profiles. The Data Support Unit in the HIV Epidemiology and Field Services Program will assist with the matching of STD/ Detox patient information with registry data. Lab data are prepared for import into the HIV registry through a rigorous process that involves examining test information and values for missing or erroneous data elements, cleaning the data as needed, matching them against existing case records, and standardizing key variables.

Because laboratories report patient viral loads over time and because NYC DOHMH can identify each case across time, it is possible to treat the surveillance data as an open cohort that individuals enter when they are first diagnosed with HIV. For example, we will use these data to quantify the time interval between individuals' HIV diagnosis date and first viral load test as a marker for HIV care initiation, as well as the interval between diagnosis date and viral suppression/durable suppression.

The HIV Surveillance Registry includes: date of birth; sex; race/ethnicity; HIV transmission risk category; ZIP code of residence at time of HIV/AIDS diagnosis; concurrent HIV/AIDS diagnosis (AIDS diagnosis within 31 days of HIV diagnosis); vital status; viral load; and CD4 count.

\section{Outcomes and analysis}

The primary outcome variable for both the STD/Detox and Surveillance cohorts is DVS within 12 months of diagnosis, which will be calculated based on viral load values in the HIV Surveillance Registry. Persons with DVS will have: 1 ) at least two suppressed viral loads ( $\leq 200$ copies $/ \mathrm{mL}$ ) within the first 12 months that are at least 90 days apart; 2) no unsuppressed intervening viral loads; 3) no unsuppressed viral load tests in the interval between achievement of DVS and the end of the 12 month period. The date of DVS will be based on the second suppressed viral load test that qualifies that person as having DVS.

For the STD/Detox cohort, the DVS outcome will be examined in two ways: more conservatively via a test of significant improvement and a priori increase of $\geq 5 \%$, and less conservatively to determine whether trends are increasing. The first hypothesis is that the proportion of subjects achieving DVS at each cohort year is different than $52 \%$ (the most recent DVS estimate at the time of study development [27]). The hypothesis will be evaluated each year using two-sided proportion z-test. With a sample size of 75 for each cohort, we have at least $80 \%$ power to detect viral suppression of $69 \%$ using a 2-sided hypothesis test with level of significance of $5 \%$. Thus, the universal ART policy will be considered to have contributed to improved DVS if we reject the null hypothesis, because the sample durable suppression proportion is significantly greater than $52 \%$. Improvement will be considered inconclusive when the conclusion of the hypothesis test is 'not having enough evidence to reject null hypothesis'. It is possible that viral suppression could worsen; this would be indicated if we reject the null hypothesis and DVS in the sample proportion is less than $52 \%$.

The second primary hypothesis is that the proportion of subjects from the Surveillance cohort that achieve DVS in each yearly cohort is different than $52 \%$. Because this cohort includes the entire population of newly HIV diagnosed cases in NYC, the proportion of subjects achieving DVS is considered a population proportion and sampling statistical techniques are not applicable. Therefore, an increase in population proportion of 
subjects achieving suppression of $\geq 5 \%$ will be considered epidemiologically meaningful. Finally, the third hypothesis associated with the primary aims will assess the increasing trend of the proportion of subjects achieving DVS over the course of the study. The hypothesis is that there will be a significant positive trend in the proportion of subjects in the STD/Detox sample achieving DVS across 4 years of the study. This aim will be analyzed using the Cochran-Armitage trend test, which is less conservative than the analysis proposed to test the two previous hypotheses and thus, has a larger chance of correctly detecting successful policies. With 300 subjects, we have $80 \%$ power to detect an overall increase of $12 \%$ from the current $52 \%$ (i.e., roughly $3 \%$ every year).

\section{Secondary outcomes}

Secondary patient-level outcomes with the STD/Detox cohort will follow other HIV treatment cascade milestones: (1) Linkage to care (time to initial visit), (2) ART initiation (time to initiation of ART), (3) HIV treatment retention (sustained engagement of regular care defined as 1 or more primary care visits in 6 months, and (4) ART adherence (self-report). Additional outcomes include quality of life, sexual risk, and drug use risk. Additional covariate and predictor data is also being collected (see Table 1). Hypotheses 1 and 3 above will also be examined with the Surveillance cohort.

\section{Qualitative in-depth interviews}

At the 6-month follow-up visit, STD/Detox cohort participants will also complete a 30-45 min qualitative interview $(n=60)$. Qualitative assessment will elicit rich descriptions of participants' experiences and motives in their own terms and language and provide complementary and elaborative data [59, 60]. Major themes will be compared and contrasted across cases over time and data will be analyzed as they are generated. If theoretical saturation is achieved for key themes before completing interviews, qualitative interviews will be stopped. Re-allocation of resources to complete additional qualitative interviews is an option should unanticipated events generate new questions.

\section{Meso-system: HIV treatment providers and primary care organizations}

HIV primary care providers $(N=60)$ practicing in NYC will be recruited to provide information on adoption and implementation of HIV treatment policies and the impact of Affordable Care Act policy changes. Eligible providers will 1) work as a primary HIV medical care provider (i.e., physician, nurse practitioner, or physician's assistant) with at least one HIV/AIDS patient on caseload (assessed at screening), and 2) be able to speak/ understand English. Providers are initially identified through three publicly available lists (HIV Medicine Association [61], American Academy of HIV Medicine [62], and the New York State AIDS Institute [63]), randomly selected, and then matched as recent reporting providers in the NYC HIV surveillance system (ordered a viral load test in 2013 or 2014 that was reported to the NYC DOHMH). Providers will be interviewed in two cross-sectional cohorts covering Years 2-3 and Years 4-5 of the project. Providers are contacted by phone and given a description of the study, invited to participate, and, if interested, scheduled for a study visit. At the scheduled meeting, written informed consent is obtained prior to completing any research assessments.

Providers complete a brief survey and in-depth interview which will take approximately 60-90 min. Table 1 displays a list of indicator domains and variables to be assessed. Quantitative survey items include: personal and professional demographics, program characteristics, organizational level attitudes and beliefs (environmental uncertainty, change-related commitment, decision-making, stress, innovativeness, autonomy, information emphasis), and patient attitudes (patients with substance use disorders, patient-practitioner orientation). The qualitative interview covers domains including: understanding of universal ART policy, process of working with newly diagnosed HIV-infected patients, role of substance use and mental health in ART initiation, challenges and facilitators to providing medical care to HIV-infected patients, challenging patient conversations, impact of the Affordable Care Act, role of NYC and New York State in HIV primary care practice, and attitudes and practice with preexposure prophylaxis (PrEP). Questions about PrEP were included as it is an important form of HIV transmission prevention for high risk populations including negative partners of PLWH. For provider-level data collection, the dimensions Adoption, Implementation, and Maintenance will be assessed (see Table 1). Provider data will be used to elucidate information regarding Adoption, Implementation and Maintenance of ART guidelines and explore: barriers and facilitators to ART initiation, retention, adherence, and viral load suppression; and changes in practice and attitudes over time.

\section{Exo-system: neighborhood analysis}

The purpose of the geospatial analyses is to examine the relationships of UHF-level exposures (specifically, socioeconomic conditions, social disorder, social cohesion, and spatial access to healthcare) to the key outcomes among the HIV Surveillance Registry cohort and patient-level STD/Detox cohort. Key outcomes include DVS, viral suppression, and other indicators along the HIV treatment cascade (linkage to care, ART initiation, and HIV care retention). These outcomes will also be explored as a function of HIV transmission category and among racial/ethnic subgroups.

\section{Data sources}

Existing administrative databases will be analyzed to describe UHF-level socioeconomic conditions (e.g., poverty 
rates, education); social disorder (e.g., alcohol outlet density); social cohesion (e.g., percent housing units leased); and spatial access to HIV-related services (e.g., HIV primary care). These environmental dimensions will be ascertained using methods based on the investigator's prior work [64-68]. For both the STD/Detox cohort and for the entire HIV Surveillance Registry cohort, ZIP code of residence at HIV diagnosis will be obtained and linked to the patients' UHF district. Each UHF district consists of 3-9 adjacent zip codes that have similar sociodemographic characteristics. The NYC DOHMH uses these districts to track and analyze local patterns of health outcomes and healthcare service delivery. Median district population size is approximately 195,000 (range: 31,000-477,500). Similar to the comprehensive STD/Detox cohorts, Reach, Efficacy and Maintenance will be assessed using all new diagnoses from the NYC DOHMH HIV Surveillance Registry (see Table 1).

\section{Analysis}

Relationships between UHF characteristics and the outcomes (i.e., viral suppression and DVS within 12 months of diagnosis) will be investigated using exploratory data analysis and multilevel modeling [69, 70]. Individuals will be nested within UHF districts, and UHF level predictors will be used to examine outcomes at the individual level. The collection of extensive data on all subjects in the STD/Detox cohort will allow for more comprehensive examination. Hierarchical regression will be used to explore significant differences between participants who achieve viral suppression and those who do not in both the HIV Surveillance Registry cohort and STD/Detox cohort to identify what factors influence differences. Such factors would potentially support reallocation of resources to increase rates of viral suppression in NYC. If the relationships between place characteristics and outcomes in the STD/Detox cohort data are similar to those found in the Surveillance cohort, we will have greater confidence that the relationships found among the smaller STD/ Detox cohort are true.

\section{Exo/macro-system: policy}

To document policy adaptation or changes that pertain to NYC, materials related to HIV testing, treatment, and prevention guidelines will be collected at the city, state and national level. These materials will include, but are not limited to, modifications to existing guidelines, committee meeting minutes, and funding decisions. Importantly, upcoming changes related to Affordable Care Act implementation, including the role of Health Homes for people living with HIV/AIDS, insurance exchanges, Medicaid expansion, and the AIDS Drug Assistance Program will be documented and assessed at the client, provider and system levels. Insurance information (and other payer data) will be collected from participants; information will also be collected from providers about reimbursement methods and how these impact patient outcomes. Policies will be archived by date to link with changes in client and provider level data.

\section{Collaborative board}

The Collaborative Board will provide the primary basis of collaborative action for grant implementation, review of ongoing data and analysis, and feedback and recommendations on policy and practice guidelines related to the HIV treatment cascade in NYC. The Board is comprised of HIV treatment providers, clinical researchers, consumers living with HIV, and NYC DOHMH representatives from the HIV Epidemiology and Field Services Program, Bureau of STD Control, and the HIV Care and Treatment Program. Study investigators will convene the board, present project data updates, and facilitate discussion. The investigative team and NYC DOHMH staff will not be present during deliberation related to specific recommendations, so that decisions remain independent of the other research processes. However, including all key stakeholders in dialogue is essential for understanding the context of policy implementation. Board meetings will be audio recorded for analytic purposes (except recommendation deliberations); recommendations will be collected and documented. The Board will meet approximately twice per year.

\section{Discussion}

This study protocol is being implemented in the context of major shifts in the local HIV epidemic, including decreasing HIV diagnosis rates. The changing context has also resulted in a reframing of state policy. In June 2014, New York State Governor Andrew Cuomo announced a plan to effectively "End the HIV Epidemic" by reducing the HIV incidence rate to below epidemic levels - from approximately 3000 cases per year to 750 cases by 2020 [71]. The plan proposes to address the following three objectives: (1) identify persons with HIV and link them to health care; (2) retain persons in health care and get them on ART to maximize viral suppression; and (3) provide access to PrEP for high-risk persons. Following this press release, the Governor appointed a Task Force to develop a set of recommendations for achieving these three objectives. The Task Force convened October 2014 through January 2015 and was comprised of over 60 community, advocacy, and academic/research experts, including Drs. Des Jarlais, Remien, and Urbina, all involved in the current project (a list of Task Force members is available here: http://www.health.ny.gov/diseases/ aids/ending_the_epidemic/docs/members.pdf). The final "blueprint" recommendations from the Task Force were approved on January 13, 2015 and were released to the 
public in April 2015. Recommendations come from four subcommittees: care, data, housing and supportive services, and prevention. The recommendation domains are complementary to data collected in the AFA Study.

The ambitious New York State goal of "Ending the Epidemic" relies in part on improvements in rates of viral load suppression. The proposed research: (1) studies a policy (universal ART) clearly aimed at ending the epidemic; (2) utilizes a mixed method design and multisystem data sources to evaluate the local success of the policy and provide a broader and more contextual understanding of PLWH treatment experiences; (3) examines neighborhood characteristics (e.g., poverty rates, social cohesion, spatial access to HIV care) that may affect the likelihood of reaching viral suppression and how place characteristics could generate racial/ethnic disparities in HIV infection; (4) assesses the policy concurrent to service changes brought about by the Affordable Care Act; and (5) in partnership with the NYC DOHMH and collaborative board members, will disseminate findings in real time throughout the funding period in the context of a rapidly changing environment. The innovative components of this project should help to produce critical public health information with broad reach.

\section{Collaborative board recommendations}

The changing context and encouraging shifts in the NYC HIV epidemic suggest the need to expand the focus of the AFA Study. At a discussion of the Collaborative Board in January 2015, there was consensus to expand the objectives of the study to focus equal time on facilitators of linkage to care, retention in care, initiation of ART, and ultimately viral suppression. In line with this shift in emphasis on what is working well, the Collaborative Board also agreed with the plan to begin enrolling any persons with HIV, in addition to newly diagnosed and out of care persons with HIV. In this way, those who are HIV positive and in care can share information on what has facilitated and supported their successful HIV care trajectories.

\section{Limitations}

Several limitations are worth noting in the design and implementation of the study. First, although the NYC DOHMH HIV Surveillance Registry is one of the best in the nation, there are data reporting and processing lags that affect the timeliness of viral load suppression analyses. An additional limitation to surveillance data is the difficulty in identifying out-migration of HIV positive individuals who have moved away from the city. A third limitation is the difficulty, already noted, in recruiting newly HIV-diagnosed individuals among a reduced number of HIV diagnoses, as well as the challenge for patients to manage their new diagnosis and feel prepared to participate in research at the same time. This recruitment challenge could lead to a higher likelihood of nonrepresentative samples. Fourth, there is no consistent definition of DVS in use; the definition proposed in the AFA Study may differ from other reports. Finally, because neighborhood level data are based on previously existing data sources, there may be placed-based constructs that are important but are unmeasurable because data are unavailable.

\section{Study status}

The AFA Study received NIH funding in July 2013 and will continue through March 2018. The first patient-level STD/Detox cohort was recruited in 2014 and Cohort 2 (January-December 2015) recruitment is underway. Recruitment of the first of two cross-sectional cohorts of providers is also underway. Initial analysis and manuscript development is underway to examine the proportion of newly diagnosed individuals (2009-2012) who reach viral load suppression and DVS within 12 months of diagnosis. This will be an analysis of geographic (UHF-level) predictors of viral load suppression as a function of HIV transmission risk (i.e., injection drug use, heterosexual sexual transmission, or male to male sexual transmission).

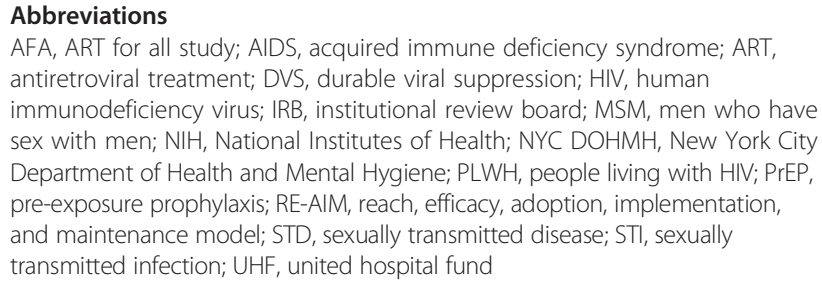
sex with men; NIH, National Institutes of Health; NYC DOHMH, New York City Department of Health and Mental Hygiene; PLWH, people living with HIV; PrEP, pre-exposure prophylaxis; RE-AIM, reach, efficacy, adoption, implementation, and maintenance model; STD, sexually transmitted disease; STI, sexually transmitted infection; UHF, united hospital fund

\section{Acknowledgements}

The authors wish to thank the individuals who conducted internal review for the New York City Department of Health and Mental Hygiene.

\section{Funding}

This work was supported by grants from the National Institutes of Health (NIH) National Institute on Drug Abuse (NIDA): R01 DA035707 (Campbell, Des Jarlais) and R01 DA003574 (Des Jarlais).

\section{Availability of data and materials}

Data collection for this study is ongoing. No data are being shared at this time.

\section{Authors' contributions}

ANCC, DDJ, ST, SB, HC, and CB conceived of the study and participated in its design. ANCC, DDJ, ST, SB, LK, CB, HC, KJ, HN, LW, MW participated in the coordination and execution of the study. ANCC and DDJ completed the first draft of manuscript. All authors read and approved the final manuscript.

\section{Competing interests}

The authors declare that they have no competing interests.

\section{Consent for publication}

Eligible and interested clients provide written informed consent prior to being formally enrolled in the study. This includes providing consent for publication of study procedures and results.

\section{Ethics approval and consent to participate}

This study is approved by the Institutional Review Board of Mount Sinai St. Luke'sRoosevelt Hospital Center, Mount Sinai Beth Israel, and the New York City 
Department of Health and Mental Hygiene. For STD and Detox patient participants, the research assistant will contact interested clients by telephone and will obtain the client's verbal consent for a short screening interview. Following screening, eligible and interested clients provide written informed consent prior to being formally enrolled in the study. HIV primary care providers are contacted by phone and given a description of the study, invited to participate, and, if interested, scheduled for a study visit. At the scheduled meeting, written informed consent is obtained prior to completing any research assessments.

\section{Author details}

'Department of Psychiatry, Columbia University Medical Center, New York State Psychiatric Institute, 1051 Riverside Drive, Box 120, New York, NY 10032, USA. ${ }^{2}$ cahn School of Medicine at Mount Sinai, 39 Broadway, 5th Floor, New York, NY 10006, USA. ${ }^{3}$ Department of Behavioral Science and Health Education, Emory University, Rollins School of Public Health, 1518 Clifton Road NE, Room 568, Atlanta, GA 30322, USA. ${ }^{4}$ New York City Department of Health and Mental Hygiene, 42-09 28th Street, Long Island City, NY 11101, USA. ${ }^{5}$ Department of Psychiatry and Behavioral Health, Mount Sinai St. Luke's Hospital, 1111 Amsterdam Avenue, 11th Floor, New York, NY 10025, USA. ${ }^{6}$ Department of Biostatistics, Mailman School of Public Health, Columbia University, 722 West 168th Street, 6th Floor, \#637, New York, NY 10032, USA.

\section{Received: 21 January 2016 Accepted: 14 July 2016}

\section{Published online: 02 August 2016}

\section{References}

1. Colfax G, Shoptaw S. The methamphetamine epidemic: implications for HIV prevention and treatment. Curr HIV/AIDS Rep. 2005;2(4):194-9.

2. Des Jarlais DC, Arasteh K, Perlis T, Hagan H, Abdul-Quader A, Heckathorn D, et al. Convergence of HIV seroprevalence among injecting and noninjecting drug users in New York City. AIDS. 2007;21:231-5.

3. Hutton HE, Lyketsos CG, Zenilman JM, Thompson RE, Erbelding EJ. Depression and HIV risk behaviors among patients in a sexually transmitted disease clinic. Am J Psychiatry. 2004;161(5):912-4

4. Raj A, Saitz R, Cheng DM, Winter M, Samet JH. Associations between alcohol, heroin and cocaine use and high risk sexual behaviors among detoxification patients. Am J Drug Alcohol Abuse. 2007:33:169-78.

5. Volkow ND, Wang GJ, Fowler JS, Telang F, Jayne M, Wong C. Stimulantinduced enhanced sexual desire as a potential contributing factor in HIV transmission. Am J Psychiatry. 2007;164(1):157-60.

6. Zule WA, Costenbader E, Coomes CM, Meyer WJ, Riehman K, Poehlman J, et al. Stimulant use and sexual risk behaviors for HIV in rural North Carolina. J Rural Health. 2007;23:573-8

7. Metsch LR, Bell C, Pereya M, Cardena G, Sullivan T, Rodriguez A, et al. Hospitalized HIV-infected patients in the era of highly active antiretroviral therapy. Am J Public Health. 2009;6:1045-9.

8. Bell C, Metsch LR, Vogenthaler N, Cardenas G, Rodriguez A, Locascio V, et al. Never in care: characteristics of HIV-infected crack cocaine users in two U.S. cities who have never been to outpatient HIV care. J Acquir Immune Defic Syndr. 2010;54(4):376-80.

9. Turner BJ, Fleishman JA, Wenger N, Londo AS, Burnam MA, Shapiro MF, et al. Effects of drug abuse and mental disorders on use and type of antiretroviral therapy in HIV-infected persons. J Gen Intern Med. 2001;16(9):625-33.

10. Hall HI, Walker F, Shah D, Belle E. Trends in HIV diagnoses and testing among U.S. adolescents and young adults. AIDS Behav. 2012;16(1):36-43.

11. Arnsten JH, Demas PA, Grant RW, Gourevitch MN, Farzadegan H, Howard $A A$, et al. Impact of active drug use on antiretroviral therapy adherence and viral suppression in HIV-infected drug users. J Gen Intern Med. 2002;17:377-81.

12. Lucas GM. Substance abuse, adherence with antiretroviral therapy, and clinical outcomes among HIV-infected individuals. Life Sci. 2011;88(21-22):948-52.

13. Hser YI, Chou CP, Hoffman V, Anglin MD. Cocaine use and high-risk sexual behavior among STD clinic patients. Sex Transm Dis. 1999;26(2):82-6.

14. Hwang L, Ross MW, Zack C, Bull L, Rickman K, Holleman M. Prevalence of STI and associated risk factors among populations of drug users. Clin Infect Dis. 2000;31:920-6.

15. Buffardi AL, Thomas KK, Holmes KK, Manhart LE. Moving upstream: Ecosocial and psychosocial correlates of sexually transmitted infections among young adults in the United States. Am J Public Health. 2008:98(6):1128-36.

16. Aktan GB, Calkins RF, Johnson DR. Substance use, need, and demand for substance user treatment services in patients treated for sexually transmitted diseases in Michigan. Subst Use Misuse. 2001;36(12):1651-76.
17. Fleming DT, Wasserheit JN. From epidemiological synergy to public health policy and practice: the contribution of other sexually transmitted diseases to sexual transmission of HIV infection. Sex Transm Infect. 1999;75:3-17.

18. Galvin SR, Cohen MS. The role of sexually transmitted diseases in HIV transmission. Nat Rev Microbiol. 2004;2(1):33-42.

19. Laga M, Manoka A, Kivuvu M, Malele B, Tuliza M, Nzila N, et al. Nonulcerative sexually transmitted diseases as risk factors for HIV-1 transmission in women: results from a cohort study. AIDS. 1993;7(1):95-102.

20. Volkow ND, Montaner J. Enhanced HIV testing, treatment, and support for HIV-infected substance users. JAMA. 2010;303(14):1423-4.

21. New York City HIV/AIDS Annual Surveillance Statistics [Internet]. New York City (NY): New York City Department of Health and Mental Hygiene; c2015 [cited 2015 Apr 16]. Available from: https://www1.nyc.gov/assets/doh/ downloads/pdf/ah/surveillance2010-table-all.pdf. Accessed 26 July 2016.

22. Des Jarlais DC, Cooper HL, Bramson H, Deren D, Hatzakis A, Hagan H. Racial ethnic disparities and implications for the prevention of HIV among persons who inject drugs. Curr Opin HIV/AIDS. 2012;7(4):354-61.

23. United States Census Bureau [Internet]. Washington (DC): U.S. Census Bureau Survey Office (US); c2013 [cited 2013 Nov 21] Available from: http://ftp2.census.gov/. Accessed 26 July 2016.

24. Torian LV, Xia Q. Achievement and maintenance of viral suppression in persons newly diagnosed with HIV, New York City, 2006-2009: using population surveillance data to measure the treatment part of "test and treat.". J Acquir Immune Defic Syndr. 2013;63(3):379-86.

25. Wiewel, EW, Torian LV, Xia Q, Braunstein A. Care and viral suppression among persons newly diagnosed with HIV: New York City 2006-2013. Oral presentation at: CROI 2015. Proceedings of the Conference on Retroviruses and Opportunistic Infections; 2015 Feb; Seattle, WA, USA

26. Terzian AS, Bodach SD, Wiewe EW, Sepkowitz K, Bernard M, Braunstein SL, et al. Novel use of surveillance data to detect HIV-infected persons with sustained high viral load and durable viorlogic suppression in New York City. PLoS One. 2012;7(1):e29679. doi:10.1371/journal.pone.0029679.

27. Stadelmann L, Terzian A, Irvine M, Braunstein S, Shepard,C. Changes in HIV viral load suppression among HIV-infected New Yorkers, 2006-2007 to 20102011. Poster presented at: CROI 2013. Proceedings of the 20th Conference on Retroviruses and Opportunistic Infections; 2013 March; Atlanta, GA, USA

28. Des Jarlais DC, Arasteh K, McKnight C, Feelemyer J, Cooper HLF, Hagan H, et al. Providing ART to HIV seropositive persons who use drugs: progress in New York City, prospects for "ending the epidemic". AIDS Behav. 2016;20(2):353-362.

29. Joint United Nations Programme on HIV/AIDS. 90-90-90: an ambitious treatment target to help end the AIDS epidemic. UNAIDS [Internet]. 2014 Oct [cited 2015 Aug 12]: [33 p.]. Available from: http://www.unaids.org/sites/ default/files/media_asset/90-90-90_en_0.pdf. Accessed 26 July 2016.

30. New York City Department of Health and Mental Hygiene [Internet]. New York (NY): New York City Department of Health and Mental Hygiene; c2011. Press release, $\mathrm{DOHMH}$ now recommends offering antiretroviral treatment to any person living with HIV, regardless the person's of CD4 count; 2011 Dec 1 [cited 2015 Aug 12]. Available from: https://a816-health30ssl.nyc.gov/ sites/nychan/Lists/AlertUpdateAdvisoryDocuments/nyc-hivarthan\%20advisory-fags.pdf. Accessed 26 July 2016.

31. Cohen MS, Chen YQ, McCauley M, Gamble T, Hosseinipour MC, Kumarasamy $\mathrm{N}$, et al. Prevention of HIV-1 infection with early antiretroviral therapy. N Engl J Med. 2011;365:493-505.

32. Cohen MS, Holmes C, Padian N, Wolf M, Hirnschall G, Lo YR, et al. HIV treatment as prevention: how scientific discovery occurred and translated rapidly into policy for the global response. Health Aff. 2012;31(7):1439-49.

33. Montaner JSG, Hogg R, Wood E, Kerr T, Tyndall M, Levy AR, et al. The case for expanding access to highly active antiretroviral therapy to curb the growth of the HIV epidemic. Lancet. 2006;368:531-6.

34. Wood E, Milloy MJ, Montaner JS. HIV treatment as prevention among injection drug users. Curr Opin HIV/AIDS. 2012;17(2):151-6.

35. Department of Health and Human Services. Panel on Antiretroviral Guidelines for Adults and Adolescents. Guidelines for the use of antiretroviral agents in HIV-1-infected adults and adolescents. DHHS [Internet]. 2015 Apr 8 [cited 2015 Aug 11]. Available from: http://www.aidsinfo.nih.gov/contentfiles/lvguidelines/ adultandadolescentgl.pdf. Accessed 26 July 2016.

36. Grinsztein B, Hosseinipour MC, Ribaudo HJ, Swindells S, Eron J, Chen YQ et al. Effects of early versus delayed initiation of antiretroviral treatment on clinical outcomes of HIV-1 infection: Results from the phase 3 HPTN 052 randomized controlled trial. Lancet Infect Dis. 2014;14(4):281-90. 
37. National Institute of Allergy and Infectious Diseases [Internet]. Bethesda (MD): National Institutes of Health; c2015. Press Release, Starting antiretroviral treatment early improves outcomes for HIV-infected individuals; 2015 May 27 [cited 2015 Aug 11]. Available from: http://www.nih.gov/news/health/ may2015/niaid-27.htm. Accessed 26 July 2016

38. Dieffenbach CW, Fauci AS. Universal voluntary testing and treatment for prevention of HIV transmission. JAMA. 2009;301(22):2380-2.

39. Granich RM, Gilks CF, Dye C, De Cock KM, Williams BG. Universal voluntary HIV testing with immediate antiretroviral therapy as a strategy for elimination of HIV transmission: a mathematical model. Lancet. 2009;373(9657):48-57.

40. Des Jarlais DC, Marmor M, Friedmann P, Titus S, Aviles E, Deren S, et al. HIV incidence among injection drug users in New York City, 1992-1997: evidence for a declining epidemic. Am J Public Health. 2001;90(3):352-9.

41. World Health Organization. Effectiveness of sterile needle and syringe programming in reducing HIV/AIDS among injecting drug users. Geneva: WHO; 2004.

42. Des Jarlais DC, Semaan S. HIV prevention for injecting drug users: the first 25 years and counting. Psychosom Med. 2008;70(5):606-11.

43. Gowing L, Farrel MF, Bornemann R, Sullivan LE, Ali R. Oral substitution treatment of injecting opioid users for prevention of HIV infection. Coch Db Syst Rev. 2011; 8: doi:10.1002/14651858.CD004145.pub4

44. Gardner EM, McLees MP, Steiner JF, del Rio C, Burman WJ. The spectrum of engagement in HIV care and its relevance to test-and-treat strategies for prevention of HIV infection. Clin Infect Dis. 2011;52:793-800.

45. New York State Department of Health. Chapter 308 of the Laws of 2010; HIV Mandated Report [Internet]. 2012 [cited 2016 Jul 26]. Available from: https://www.health.ny.gov/diseases/aids/providers/testing/law/docs/ chapter_308.pdf. Accessed 26 July 2016.

46. New York City Department of Health and Mental Hygiene. The Bronx knows HIV testing initiative: final report. NYDOHMH [Internet]. 2011 [cited 2015 Jun 15]. Available from: https:/www1.nyc.gov/assets/doh/downloads/pdf/ah/bronxknows-summary-report.pdf. Accessed 26 July 2016.

47. Patient Protection and Affordable Act [Internet]. 2010 [cited 2016 Jul 26]. Available from: https://www.gpo.gov/fdsys/pkg/PLAW-111publ148/pdf/ PLAW-111publ148.pdf. Accessed 26 July 2016.

48. Glasgow RE, Vogt TM, Boles SM. Evaluating the public health impact of health promotion interventions: The RE-AIM framework. Am J Public Health. 1999;89:1322-7.

49. Bronfenbrenner U. The ecology of human development. Cambridge: Harvard University Press; 1979.

50. Kurtz SP, Buttram ME, Surratt HL, Stall RD. Resilience, syndemic factors, and serosorting behaviors among HIV-positive and HIV-negative substance-using MSM. AIDS Educ Prev. 2012;24(3):193-205.

51. Singer MC, Erickson PI, Badiane L, Diaz R, Ortiz D, Abraham T, et al. Syndemics, sex and the city: understanding sexually transmitted diseases in social and cultural context. Soc Sci Med. 2006;63:2010-21.

52. Bronfenbrenner U, Ceci SJ. Nature-nurture reconceptualized in developmental perspective: A bioecological model. Psychol Rev. 1994;101(4):568-86.

53. Bronfenbrenner U, Evans GW. Developmental science in the $21^{\text {st }}$ century: emerging questions theoretical models, research designs and empirical findings. Soc Dev. 2000;9(1):115-25.

54. Bronfenbrenner $U$, Morris PA. The ecology of developmental processes. In: Lerner RM, editor. Handbook of child psychology. New York: Wiley; 1998. p. 993-1028.

55. Bronfenbrenner U. Toward an experimental ecology of human development. Am Psychol. 1977;32:513-30.

56. National Institute on Alcohol Abuse and Alcoholism. Rethinking drinking: alcohol and your health. National Institutes of Health [Internet]. 2010 [cited 2012 Sep 6]. Available from: http://pubs.niaaa.nih.gov/publications/ RethinkingDrinking/Rethinking_Drinking.pdf. Accessed 26 July 2016.

57. Des Jarlais DC, Arasteh K, McKnight C, Hagan H, Perlman DC, Semaan D. Associations between Herpes Simplex Virus Type 2 and HCV with HIV among injecting drug users in New York City: the current importance of sexual transmission of HIV. Am J Public Health. 2011;101(7):1277-83.

58. Jenness S, Myers JE, Neaigus A, Lulek J, Navejas M, Raj-Singh S. Delayed entry into HIV medical care after HIV diagnosis: risk factors and research methods. AIDS Care. 2012;24(10):1240-8.

59. Landsverk J, Brown CH, Chamberlain P, Palinkas L, Ogihara M, Czaja S, et al. Design and analysis in dissemination and implementation research. In: Brownson RC, Colditz GA, Proctor EK, editors. Dissemination and implementation research in health. New York: Oxford University Press; 2012. p. 225-60.
60. Palinkas LA, Aarons GA, Horwitz S, Chamberlain P, Hurlburt M, Landsverk J. Mixed method designs in implementation research. Adm Policy Ment Health. 2011;38:44-53.

61. HIV Provider Directory [Internet]. Arlington (VA): HIV Medicine Association. c2012. - [cited 2013 Dec 12]. Available from: http://www.hivma.org/Home. aspx. Accessed 26 July 2016.

62. The American Academy of HIV Medicine Referral Link [Internet]. Washington (DC): The American Academy of Medicine. c2001. - [cited 2013 Dec 12]. Available from: http://www.aahivm.org/ReferralLink/exec/frmAdvSearch.aspx. Accessed 26 July 2016.

63. New York State Department of Health AIDS Institute Provider Database [Internet]. Albany (NY): New York State Department of Health. c2013. - [cited 2013 Dec 12]. Available from: http://www.health.ny.gov/diseases/aids/general/ resources/resource_directory/nyc_region/index.htm. Accessed 26 July 2016.

64. Cooper HLF, Des Jarlais DC, Ross Z, Tempalski B, Bossak B, Friedman SR. Spatial access to syringe exchange programs and pharmacies selling over-the-counter syringes predicts drug injectors' use of sterile syringes. Am J Public Health. 2011;86(6):929-45.

65. Cooper HLF, Des Jarlais DC, Tempalski B, Bossak BH, Ross Z, Friedman SR. Drug-related arrest rates and spatial access to syringe exchange programs in New York City health districts: combined effects on the risk of injectionrelated infections among injectors. Health Place. 2012;18(2):218-28.

66. Cooper HLF, Wypij D, Krieger N. Police drug crackdowns and hospitalization rates for illicit-injection-related infections in New York City. Int J Drug Policy. 2005:16:150-60.

67. Cooper HLF, Des Jarlais DC, Tempalski B, Bossak BH, Ross Z, Friedman SR. Spatial access to sterile syringes and the odds of injecting with an unsterile syringe among injectors: a longitudinal multilevel study. J Urban Health. 2012;89(4):678-96.

68. Friedman SR, Cooper HLF, Tempalski B, Keem M, Friedman R, Flom PL, et al. Relationships of deterrence and law enforcement to drug-related harms among drug injectors in U.S.A. metropolitan areas. AIDS. 2006;20(1):93-9.

69. Hartwig F, Dearing B. Exploratory data analysis. Thousand Oaks: Sage Publications; 1979.

70. Hox JJ. Multilevel analysis: Techniques and applications. New York: Routledge; 2010.

71. Cuomo, AM [Internet]. Albany (NY): New York State Government; c2015. Press release, Governor Cuomo announces plan to end the AIDS epidemic in New York State; 2014 Jun 29 [cited 2015 Aug 11]. Available from: http://www.governor.ny.gov/news/governor-cuomo-announces-plan-endaids-epidemic-new-york-state. Accessed 26 July 2016.

72. Gianotti N, Galli L, Bocchiola B, Cahua T, Panzini P, Zandonà D, et al. Number of daily pills, dosing schedule, self-reported adherence and health status in 2010: a large cross-sectional study of HIV-infected patients on antiretroviral therapy. HIV Med. 2013;14(3):153-60.

73. Kalichman SC, Amaral CM, Swetzes C, Jones M, Macy R, Kalichman MO. A simple single item rating scale to measure medication adherence: further evidence for convergent validity. J Int Assoc Physicians AIDS Care. 2009:8(6):367-74.

74. Newville H, Sorensen JL. The efficacy of a computerized assessment of medication adherence in active substance users. J Int Assoc Physicians AIDS Care. 2013;12(4):232-5.

75. The EuroQol Group. EuroQol-a new facility for the measurement of healthrelated quality of life. Health Policy. 1990;16(3):199-208.

76. Booth RE, Watters JK, Chitwood DD. HIV risk-related sex behaviors among injection drug users, crack smokers, and injection drug users who smoke crack. Am J Public Health. 1993;83:1144-8.

77. National Institute on Drug Abuse, National AIDS Research Project. Risk behavior assessment questionnaire. Washington: DHHS; 1993.

78. Sobell LC, Sobell MB. Timeline follow-back: a technique for assessing selfreported alcohol consumption. In: Litten RZ, Allen JP, editors. Measuring alcohol consumption: psychosocial and biological methods. Totowa: Humana Press; 1992. p. 41-72.

79. Heatherton TF, Kozlowski LT, Frecker RC, Fagerström KO. The Fagerström Test for Nicotine Dependence: A revision of the Fagerström Tolerance Questionnaire. Br J Addict. 1991;86:1119-27.

80. American Psychiatric Association. Diagnostic and statistical manual of mental disorders. fifthth ed. Arlington: American Psychiatric Association; 2013. p. 947.

81. Kessler RC, Andrews G, Colpe LJ, Hiripi E, Mroczek DK, Normand SLT, et al. Short screening scales to monitor population prevalences and trends in non-specific psychological distress. Psychol Med. 2002;32(6):959. 
82. Krueger RF, Markon KE. The role of the DSM-5 Personality Trait Model in moving toward a quantitative and empirically based approach to classifying personality and psychopathology. Annu Rev Clin Psychol. 2014;10:477-501.

83. Sherbourne CD, Stewart AL. The MOS social support survey. Soc Sci Med. 1991;32(6):705-14.

84. Remien RH, Mellins CA, Robbins RN, Kelsey R, Rowe J, Warne P, et al. Masivukeni: Development of a multimedia based antiretroviral therapy adherence intervention for counselors and patients in South Africa. AIDS Behav. 2013;17(6):1979-91.

85. McLellan AT, Alterman Al, Cacciloa J, Metzger D, O'Brien CP. A new measure of substance abuse treatment: initial studies of the treatment service review. J Nerv Ment Dis. 1800;1992:101-10.

86. Bodenlos JS, Gorthe KB, Kendra K, Whitehead D, Copeland AL, Brantley PJ. Attitudes toward HIV health care providers scale: development and validation. AIDS Patient Care STDS. 2004;18(12):714-20.

87. LaVeist TA, Isaac LA, Williams KP. Mistrust of health care organizations is associated with underutilization of health services. Health Serv Res. 2009;44(6):2093-105.

88. Chesney MA, Ickovics JR, Chambers DB, Gifford AL, Neidig J, Zwickl B. Selfreported adherence to antiretroviral medications among participants in HIV clinical trials: the AACTG adherence instruments. Patient Care Committee \& Adherence Working Group of the Outcomes Committee of the Adult AIDS Clinical Trials Group (AACTG). AIDS Care. 2000;12(3):255-66.

89. Williams DR, Yu Y, Jackson JS, Anderson NB. Racial differences in physical and mental health: socioeconomic status, stress, and discrimination. J Health Psychol. 1997;2(3):335-51.

90. Fife BL, Wright ER. The dimensionality of stigma: a comparsion of its impact on the self of persons with HIV/AIDS and cancer. J Health Soc Behav. 2000;41:50-67.

91. Wagner GJ, Remien RH, Dolezal C, Carballo-Dieguez A. Correlates of adherence to combination antiretroviral therapy among HIV+ members of HIV mixed status couples. AIDS Care. 2002;14(1):105-9.

92. Wagner GJ, Kanouse DE, Koegel P, Sullivan G. Correlates of HIV antiretroviral adherence in persons with serious mental illness. AIDS Care. 2004;16(4):501-6.

93. Neubert MJ, Cady SH. Program commitment: a multi-study longitudinal field investigation of its impact and antecedents. Pers Psychol. 2001;54:421-48.

94. Hollenbeck JR, O'Leary AM, Klein HJ, Wright PM. Investigation of the construct validity of a self-report measure of goal commitment. J Appl Psychol. 1989;74(6):951-6.

95. Ohman-Strickland PA, Orzano AJ, Nutting PA, Dickinson WP, Scott-Cawiezell J, Hahn K, et al. Measuring organizational attributes of primary care practices: development of a new instrument. Health Serv Res. 2007;42(3):257-1273.

96. Kralewski J, Dowd BE, Kaissi A, Curoe A, Rockwood. Measuring the culture of medical group practices. Health Care Manage Rev. 2005;30(3):184-93.

97. Barone EJ, Huggett KN, Lofgreen AS. Investigation of students' attitudes about patients with substance use disorders before and after completing an online curricular module. Ann Behav Sci Med Educ. 2001;17(1):10-3.

98. Ding L, Landon BE, Wilson IB, Wong MD, Shapiro MF, Cleary PD. Predictors and consequences of negative physician attitudes toward HIV-infected injection drug users. Arch Intern Med. 2005;165:618-23.

99. Krupat E, Rosenkranz SL, Yeager CM, Barnard K, Putnam SM, Inui TM. The practice orientations of physicians and patients: the effect of doctor-patient congruence on satisfaction. Patient Educ Couns. 2000;39:49-59.

100. United States Census Bureau. 2007 - 2011 American community survey. U.S. Census Bureau's American Community Survey Office [Internet]. 2013 [cited 2013 Nov 13]. Available from: http://ftp2.census.gov/. Accessed 26 July 2016.

101. United States Census Bureau. 2009 U.S. Census Bureau's zip code business patterns. U.S. Census Bureau Survey Office [Internet]. 2014 [cited 2014 Mar 3] Available from: http://ftp2.census.gov/. Accessed 26 July 2016.

102. United States Census Bureau. 2011 U.S. Census Bureau's zip code business patterns. U.S. Census Bureau Survey Office [Internet]. 2013 [cited 2013 Nov 21]. Available from: http://ftp2.census.gov/. Accessed 26 July 2016.

103. United States Census Bureau. 2012 U.S. Census Bureau's zip code business patterns. U.S. Census Bureau Survey Office [Internet]. 2014 [cited 2014 Jul 3]. Available from: http://ftp2.census.gov/. Accessed 26 July 2016.

104. United States Postal Service. 2009 DelStat. U.S. Postal Service [Internet]. 2014 [cited 2014 Mar 6]. Available from: http://www.usps.gov/. Accessed 26 July 2016.

105. United States Postal Service. 2010 DelStat. U.S. Postal Service [Internet]. 2013 [cited 2013 Nov 21] Available from: http://www.usps.gov/. Accessed 26 July 2016.
106. United States Postal Service. 2012 DelStat. U.S. Postal Service [Internet]. 2014 [cited 2014 Mar 6. Available from: http://www.usps.gov/. Accessed 26 July 2016.

107. United States Census Bureau. 2007 - 2011 American community survey. U.S. Census Bureau's American Community Survey Office [Internet]. 2014 [cited 2014 Aug 25]. Available from: http://ftp2.census.gov/. Accessed 26 July 2016.

\section{Submit your next manuscript to BioMed Central and we will help you at every step:}

- We accept pre-submission inquiries

- Our selector tool helps you to find the most relevant journal

- We provide round the clock customer support

- Convenient online submission

- Thorough peer review

- Inclusion in PubMed and all major indexing services

- Maximum visibility for your research

Submit your manuscript at www.biomedcentral.com/submit
Ciomed Central 